\title{
Penilaian Kinerja Sistem Irigasi Utama Daerah Irigasi Bantimurung Kabupaten Maros
}

\section{(Evaluation Performance of the Main Irrigation System in Bantimurung Irrigation Area, Maros Regency)}

\author{
Siti Masita Fachrie ${ }^{1 *)}$, Mahmud Achmad ${ }^{2)}$ dan Samsuar $^{3)}$ \\ 1) Program Studi Keteknikan Pertanian Universitas Hasanuddin \\ 2) Program Studi Keteknikan Pertanian Universitas Hasanuddin \\ 3) Program Studi Keteknikan Pertanian Universitas Hasanuddin \\ *) Email korespondensi: masyitafachrie@ yahoo.co.id
}

\begin{abstract}
ABSTRAK
Bangunan irigasi mengalami penurunan fungsi akibat bertambahnya umur bangunan atau pengaruh ulah manusia. Sesuai dengan amanat Menteri Pekerjaan Umum dan Perumahan Rakyat (PUPR) No. 12/PRT/M/2015 bahwa evaluasi kinerja sistem irigasi dimaksudkan untuk mengetahui kondisi kinerja sistem irigasi, agar kebutuhan air tanaman dapat tercapai dengan optimal. Sistem irigasi dipengaruhi oleh beberapa aspek, yaitu: prasarana fisik, produktifitas tanam, sarana penunjang, organisasi personalia, dokumentasi, dan Perkumpulan Petani Pemakai Air (P3A). Tujuan dari penelitian ini untuk melakukan penilaian tentang kinerja sistem irigasi Utama Bantimurung Kabupaten Maros yang berguna untuk menyusun program tindak lanjut seperti perbaikan, rehabilitasi, dan pemeliharan jaringan irigasi. Metode penelitian dilakukan dengan cara obeservasi langsung ke lapangan dengan melakukan penelusuran jaringan irigasi DI Bantimurung, wawancara dan analisis data sekunder. Penelusuran jaringan irigasi ini dilakukan untuk mendapatkan data kondisi prasarana fisik. Metode wawancara dan analisis data sekunder digunakan untuk mendapatkan data produktivitas tanam, sarana penunjang, organisasi personalia, dokumentasi dan P3A. Hasil yang diperoleh menunjukkan kinerja sistem irigasi utama daerah irigasi Bantimurung ialah Kurang dan Perlu Perhatian (55,41\%). Perhitungan penilaian kinerja sistem irigasi Bantimurung meliputi 6 aspek indikator yaitu kondisi prasarana fisik, produktivitas tanam, sarana penunjang, organisasi personalia, dokumentasi dan Perkumpulan Petani Pemakai Air (P3A).
\end{abstract}

Kata Kunci: DI Bantimurung, Penilaian, Kinerja, Daerah Irigasi.

\section{PENDAHULUAN}

\section{Latar Belakang}

Keterbatasan air pada musim kemarau menyebabkan kebutuhan air tanaman tidak terpenuhi dan menurunkan hasil produksi pertanian. Sehingga Air menjadi salah satu faktor yang mempengaruhi pertumbuhan, dan peningkatan produksi pertanian, ketersediaanya mutlak diperlukan, baik secara jumlah maupun kualitasnya.
Pemberian air pada lahan pertanian menjadi prioritas utama pembangunan Indonesia.

Salah satu upaya yang dilakukan pemerintah dalam pemenuhan kebutuhan air dengan mendirikan sistem irigasi. Dengan demikian kebutuhan air tanaman setiap musimnya dapat terpenuhi. Hal ini sesuai dengan Peraturan pemerintah (PP) No. 20 Tahun 2006 tentang irigasi mengamanatkan bahwa pengembangan dan pengelolahan irigasi dilakukan oleh petani dan pemerintah sesuai dengan arasnya. Irigasi menjadi pendukung keberhasilan 
pembangunan pertanian dan kebijakan pemerintah yang strategis untuk mempertahankan swasembada pangan.

Sehingga diperlukan pengelolaaan dan perhatian khusus dalam memanenjemen sumber daya air. Pengelolaan yang dimaksudkan adalah peningkatan kinerja pendistribusian dan pengalokasian secara efektif dan efisien pada setiap saluran irigasi, sehingga memberikan air dengan kondisi tepat mutu, tepat ruang, dan tepat waktu.

Untuk mendukung hal tersebut Mentri Pekerjaan Umum dan Rumah Rakyat mengeluarkan peraturan No. 12/PRT/M/2015 yang mengamanatkan, bahwa evaluasi kinerja sistem irigasi dimaksudkan untuk mengetahui kondisi kinerja sistem irigasi. Hal ini selaras dengan surat Mentri Koordinator Bidang Perekonomian No. S-44 tahun 2016 tentang pendataan dan pengembangan sistem irigasi yang substansinya antara lain meminta Mentri Pekerjaan Umum dan Perumahan Rakyat melakukan penilaian kinerja sistem irigasi secara lengkap pada sistem irigasi (sistem irigasi utama dan sistem irigasi tersier). Berdasarkan permasalahan yang telah dipaparkan maka perlu dilakukan penelitian Penilaian Kinerja Sistem Irigasi Utama Daerah Irigasi Bantimurung Kabupaten Maros untuk mengetahui kinerja sistem irigasi utama.

\section{Tujuan dan Kegunaan}

Tujuan dari penelitian ini untuk melakukan penilaian tentang kinerja sistem irigasi Utama Bantimurung Kabupaten Maros yang menjadi kewenangan pemerintah kabupaten yang selanjutnya berguna untuk menyusun program tindak lanjut seperti perbaikan, rehabilitasi, serta operasi dan pemeliharan jaringan irigasi.

\section{METODOLOGI PENELITIAN}

\section{Alat dan Bahan}

Alat yang digunakan pada penelitian ini terbagi menjadi 2 yaitu Perangkat keras,
GPS (Global Positioning Sistem), Current meter, Kamera, Laptop, Meteran, dan ATK. Sedangkan Perangkat lunak yaitu, Software Microsft Axcel, Google Earth, Arcgis.

Bahan yang digunakan pada penelitian ini yaitu, peta citra satelit, Peta DI, Skema dan Jaringan Irigasi.

\section{Prosedur Penelitian}

Adapun prosedur penelitian penilaian kinerja sistem irigasi utama ini dilakukan dengan langkah-langkah sebagai berikut:

\section{Persiapan}

Pada tahap ini dilakukan persiapan alat dan bahan, surat perizinan pengambilan data pada instansi terkait serta form penilaian kinerja irigasi.

\section{Pengumpulan data}

Data yang diperlukan dalam penelitian yaitu data primer dan data sekunder.

\section{Data Primer}

Data yang diperoleh dengan cara pengukuran dan survei yaitu, data koordinat letak bangunan irigasi, data kondisi prasarana fisik irigasi. Sedangkan data yang diperoleh dengan cara wawancara yaitu, data tugas dan tanggung jawab organisasi pelaksana irigasi dan inventarisasi dan kondisi kelembagaan IP3A/GP3A/P3A daerah irigasi Bantimurung.

\section{Data Sekunder}

Data sekunder yaitu data yang diperoleh dari instansi yang terkait, data sekunder meliputi:

1. Luas wilayah Daerah Irigasi (termasuk data luasan baku, luas potensial, luas fungsional)

2. Peta daerah irigasi Bantimurung

3. Skema jaringan irigasi dan skema bangunan irigasi

4. Data inventarisasi prasarana fisik irigasi (bangunan utama, bangunan pelengkap, saluran pembawa dan pembuangan serta bangunan bagi, bangunan sadap)

5. Data inventarisasi tenaga operasi dan pemeliharaan daerah irigasi

6. Data inventarisasi sarana dan prasaran OP

7. Data inventarisasi IP3A/GP3A/P3A 
8. Data inventarisasi produktifitas tanaman (luas tanam dan luas panen dan produktivitas padi) pada wilayah pelayanan irigasi bantimurung

9. Susunan organisasi pelaksana (OP) daerah irigasi Bantimurung

10. Susunan organisasi P3A/GP3A daerah irigasi Bantimurung

11. Data debit kebutuhan/rencana maksimum

12. Data produktifitas tanaman

\section{Survei dan Inventarisasi}

Inventarisasi jaringan irigasi dilakukan untuk mendapatkan data jumlah, dimensi, dan fungsi seluruh aset irigasi. Sedangkan survei untuk mengetahui kondisi seluruh aset irigasi. Survei dan inventarisasi prasarana pada jaringan dilakukan dengan menggunakan blanko inventarisasi jaringan irigasi (terlampir) meliputi:

1. Inventarisasi data prasarana fisik irigasi (bangunan utama, saluran dan bangunan bagi, bangunan sadap)

2. Inventarisasi data tenaga operasi dan pemeliharaan daerah irigasi

3. Inventarisasi data sarana dan prasaran $\mathrm{OP}$

4. Inventarisasi data IP3A/GP3A/P3A

5. Inventarisasi data indeks pertanaman dan produktivitas padi pada wilayah pelayanan irigasi bantimurung

\section{Penilaian Indeks Kinerja Jaringan} Irigasi Utama

Pada proses ini penilaian kinerja sistem jaringan irigasi utama dilakukan dengan pengisian form indeks kinerja (terlampir), yang mengacu pada pedoman Penilaian Kinerja Sistem Irigasi (Permukaan) Kewenangan Pusat, Kementrian Pekerjaan Umum dan Perumahan Rakyat, Direktoral Jenderal Sumber Daya Air, 2017. Analisis penilaian kinerja dilakukan sesuai dengan pembobotan yang telah ditetapkan. Tahapan analisis diuraikan sebagai berikut;

Prasarana fisik (45\%)

Penilaian kinerja komponen prasarana fisik dilakukan dengan mengevaluasi 6 kompenen yaitu:
1. Bangunan Utama meliputi bendung, pintu-pintu bendung, kantong lumpur dan pintu penguras.

2. Saluran pembawa meliputi kapasitas saluran, dan tinggi tanggul.

3. Bangunan pada saluran pembawa meliputi bangunan pengatur (seperti Bagi/Bagi Sadap/Sadap), bangunan pelengkap, dan pengukuran debit padasetiap bangunan pengatur.

4. Saluran Pembuangan dan bangunannya.

5. Jalan masuk/inspeksi

6. Kantor, perumahan, dan gudang

Sarana penunjang (10\%)

Penilaian kinerja komponen prasarana penunjang dilakukan dengan mengevaluasi 4 komponen yaitu:

1. Peralatan O\&P

2. Transportasi

3. Alat komunikasi

4. Alat kantor Ranting/Pengamat/ UPTD

\section{Produktivitas tanaman (15\%)}

Penilaian kinerja komponen prasarana penunjang dilakukan dengan mengevaluasi 3 komponen yaitu:

1. Pemenuhan kebutuhan air

2. Realisasi luas tanam.

3. Produktivitas padi

\section{Organisasi Personalia (15\%)}

Penilaian kinerja organisasi personalia dilakukan dengan mengevaluasi komponen yaitu:

1. Organisasi O\&P telah disusun dengan tugas dan batasan tanggung jawab yang jelas.

2. Personalia

\section{Komponen dokumentasi (5\%)}

Penilaian dokumentasi pada sistem irigasi utama dilakukan dengan mengevaluasi 2 komponen yaitu:

1. Buku data DI (Daerah irigasi)

2. Peta dan gambar (skema DI, Skema Bangunan, dan petaikhtisar)

\section{Kondisi kelembagaan Perkumpulan Petani Pemakai Air (P3A) (10\%)}

Penilaian kinerja P3A sistem irigasi utama dilakukan dengan mengevaluasi 4 komponen yaitu:

1. GP3A/IP3A yang berbadan hukum

2. Kondisi kelembagaan 
3. Rapat ulu-ulu/P3A Desa/GP3A/ IP3A dengan Rating/Pengamat/ UPTD

4. Partisipasi GP3A/IP3A

\section{Penentuan Kondisi}

Dalam penentuan Kondisi penilaian dibagi dalam beberapa kelompok kondisi sebagai berikut:

1) Untuk prasarana fisik

a) Kondisi baik sekali (>90-100\%) atau tingkat kerusakan $(\leq 0-10 \%)$

b) Kondisi baik $\quad(>80-90 \%) \quad$ atau tingkat kerusakan $(\leq 10-20 \%)$

c) Kondisi sedang ( $>60-80 \%)$ atau tingkat kerusakan $(\leq 20-40 \%)$

d) Kondisi kurang $(<60 \%)$ atau tingkat kerusakan $(\geq 40 \%)$

Pengolahan data dan pembuatan Peta daerah irigasi

Pada tahap ini terdapat 2 jenis data yang akan dikelolah yaitu data hasil penilaian kinerja irigasi dan peta daerah irigasi. Pengolahan data kinerja irigasi dengan menggunakan software Microsof Excel untuk menghitung bobot dari kinerja irigasi, sedangkan untuk peta daerah irigasi dibuat dengan software Arcgiss sehingga menghasilkan peta Kondisi Jaringan Utama Daerah Irigasi Bantimurung.

\section{Output}

Output dari penelitian ini berupa nilai kinerja jaringan irigasi utama dan peta kondisi saluran pembawa dan bangunan Jaringan Utama Daerah irigasi Bantimurung.

\section{Diagram Alir Penelitian}

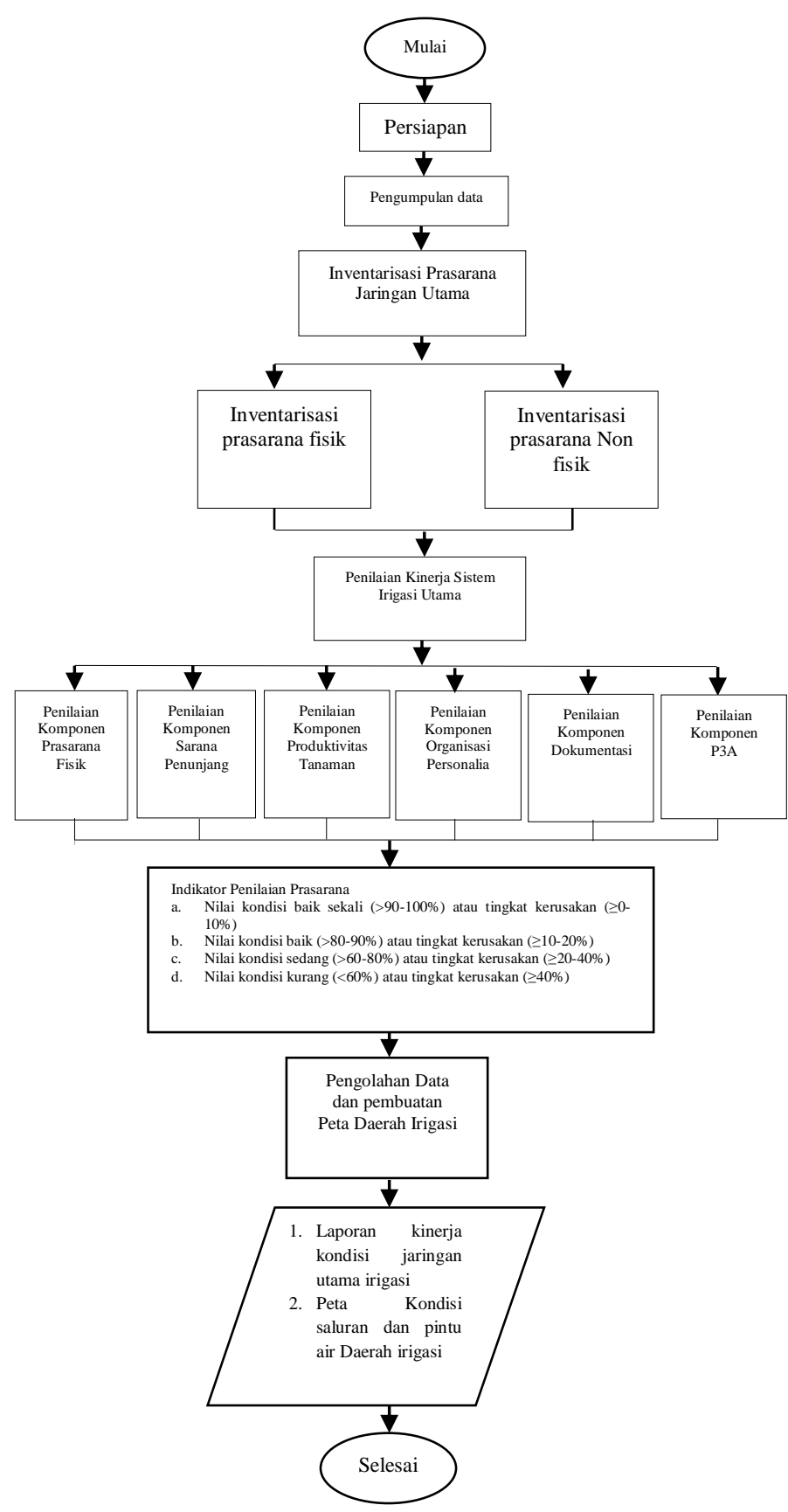

Gambar 1. Diagram Alir Penelitian 


\section{HASIL DAN PEMBAHASAN}

\section{Kondisi Umum DI Bantimurung}

Daerah Irigasi (DI) Bantimurung secara astronomi terletak antara $119^{\circ} 40^{\prime} 05^{\prime \prime}-119^{\circ} 47^{\prime} 40^{\prime \prime}$ BT dan 04 59'20"'$05^{\circ} 05^{\prime} 50^{\prime \prime} \quad$ LS. Daerah aliran sungai Bantimurung merupakan anakan sungai utama dari sistem DAS Maros yang mencakup empat wilayah yaitu Bantimurung, Cenrana, Tompobulu, dan Simbang. Luas baku Daerah Irigasi Bantimurung 6.513 ha, mencakup enam kecamatan yaitu Maros Baru, Lau, Bontoa, Simbang, Bantimurung, dan Turikale.

\section{Analisis Kinerja Sistem Irigasi Kondisi Prasarana Fisik}

Penilaian kondisi prasarana fisik dilakukan dengan menelusuri jaringan irigasi. Penelusuran dilakukan mulai dari hulu ke hilir. Kondisi prasaran irigasi mempunyai nilai bobot maksimum $45 \%$. Uraian penilaian kinerja pada prasarana fisik dapat dilihat pada Tabel 1 .

Tabel 1. Penilaian kinerja prasarana fisik sistem irigasi utama daerah irigasi Bantimurung

\begin{tabular}{|c|c|c|c|}
\hline No & Uraian & $\begin{array}{c}\text { Kondisi } \\
\text { Eksisting } \\
(\%)\end{array}$ & $\begin{array}{c}\text { Bobot } \\
\text { Maks }(\%)\end{array}$ \\
\hline (1) & (2) & (3) & (4) \\
\hline 1 & Bangunan utama & 9,82 & 13 \\
\hline 2 & $\begin{array}{l}\text { Saluran } \\
\text { pembawa }\end{array}$ & 4,82 & 10 \\
\hline 3 & $\begin{array}{l}\text { Bangunan pada } \\
\text { saluran } \\
\text { pembawa }\end{array}$ & 4,53 & 9 \\
\hline 4 & $\begin{array}{l}\text { Saluran } \\
\text { pembuangan dan } \\
\text { bangunannya }\end{array}$ & 0,66 & 4 \\
\hline 5 & $\begin{array}{l}\text { Jalan } \\
\text { masuk/inspeksi }\end{array}$ & 3,30 & 4 \\
\hline 6 & $\begin{array}{l}\text { Kantor, } \\
\text { perumahan dan } \\
\text { gudang }\end{array}$ & 2,18 & 5 \\
\hline \multicolumn{2}{|c|}{$\begin{array}{c}\text { Total bobot Prasarana } \\
\text { Fisik }\end{array}$} & 25.17 & 25,17 \\
\hline
\end{tabular}

\section{Kondisi Bangunan Utama}

Penilaian pada bangunan utama mengalami perubahan pembobotan karena adanya penyesuaian kondisi lapangan. Perubahan pembobotan pada bangunan utama dilakukan karena tidak adanya kantong lumpur bendung. Uraian penilaian dapat dilihat pada tabel 2 .

Tabel 2. Penilaian kinerja sistem irigasi bantimurung pada komponen bangunan utama tanpa kantong lumpur

\begin{tabular}{|c|c|c|c|c|}
\hline \multirow[b]{2}{*}{ Uraian } & \multirow{2}{*}{$\begin{array}{c}\text { Kondisi } \\
\text { Eksisting } \\
(\%)\end{array}$} & \multirow{2}{*}{$\begin{array}{c}\text { Nilai } \\
\text { Bagian } \\
(\%)\end{array}$} & \multicolumn{2}{|c|}{$\begin{array}{l}\text { Indeks } \\
\text { Kondisi }\end{array}$} \\
\hline & & & $\begin{array}{c}\text { Bobot } \\
\text { Final } \\
(\%)\end{array}$ & $\begin{array}{c}\text { Bobot } \\
\text { Maks } \\
(\%) \\
\end{array}$ \\
\hline (1) & (2) & (3) & (4) & (5) \\
\hline 1. Bendung & 65,4 & 100 & 3,27 & 5 \\
\hline $\begin{array}{l}\text { 2. Pintu- } \\
\text { pintu } \\
\text { Bendung }\end{array}$ & 81,8 & 100 & 6,55 & 8 \\
\hline $\begin{array}{l}\text { 3. Kantong } \\
\text { lumpur } \\
\text { dan pintu } \\
\text { penguras }\end{array}$ & 0 & 100 & 0 & 0 \\
\hline $\begin{array}{c}\text { Total Bobot } \\
\text { Bangunan } \\
\text { Utama }\end{array}$ & 75,5 & & 9,82 & 13 \\
\hline $\begin{array}{c}\text { Hasil } \\
\text { menunjukkan }\end{array}$ & $\begin{array}{r}\text { penilai } \\
\mathrm{k}\end{array}$ & iponen & & $\begin{array}{l}\text { tabel } \\
\text { yang }\end{array}$ \\
\hline
\end{tabular}

berkonstribusi tinggi yaitu pintu-pintu bendung (6,55\%). Sedangkan yang berkonstribusi rendah ialah komponen kantong lumpur dan pintu penguras $(0 \%)$. Di lapangan pintu penguras mempunyai fungsi ganda yaitu untuk mencegah sedimen kasar masuk kesaluran irigasi dan untuk mengendapkan frasik kasar maupun fraksi halus agar tidak masuk ke dalam jaringan irigasi.

\section{Kondisi Saluran Pembawa}

Komponen penilaian kondisi saluran pembawa terdiri dari kapasitas tiap saluran, tinggi tanggul dan perbaikan saluran.

Penilaian kondisi saluran pembawa memiliki nilai bobot maksimum $10 \%$. Hasil penilaian komponen kapasitas tiap saluran cukup untuk membawa debit kebutuhan bernilai $3,23 \%$ dari bobot maks $5 \%$ yang diharapkan. Sedangkan komponen tinggi tanggul cukup untuk menghindari limpahan bernilai $0,58 \%$ dari bobot maks $2 \%$ yang diharapkan. Dan untuk perbaikan saluran bernilai $1,01 \%$ dari bobot maks $3 \%$ yang diharapkan. 
Komponen yang berkonstribusi tinggi yaitu kapasitas tiap saluran $(3,32 \%)$ dan yang berkonstribusi rendah yaitu komponen tinggi tanggul $(0,58 \%)$. Di lapangan tinggi tanggul tidak dapat menampung debit maks atau debit pada musim hujan karena tanggul tidak memiliki tinggi jagaan yang seuai dengan standar PU dimana tinggi jagaan untuk saluran primer $100 \mathrm{~cm}$ dan tinggi jagaan untuk saluran sekunder 50 $\mathrm{cm}$, hal ini sesuai dengan kriteria penilaian. Penilaian ini dapat diuraikan sebagaimana pada Tabel 3.

Tabel 3. Penilaian kinerja sistem irigasi Bantimurung pada komponen saluran pembawa

\begin{tabular}{|c|c|c|c|c|}
\hline \multirow[b]{2}{*}{ Uraian } & \multirow[b]{2}{*}{$\begin{array}{c}\text { Kondisi } \\
\text { Eksisting } \\
(\%)\end{array}$} & \multirow[b]{2}{*}{$\begin{array}{c}\text { Nilai } \\
\text { Bagian } \\
(\%)\end{array}$} & \multicolumn{2}{|c|}{ Indeks Kondisi } \\
\hline & & & $\begin{array}{c}\text { Bobot } \\
\text { Final } \\
(\%)\end{array}$ & $\begin{array}{c}\text { Bobot } \\
\text { Maks } \\
(\%)\end{array}$ \\
\hline (1) & (2) & (3) & (4) & (5) \\
\hline $\begin{array}{l}\text { 1. Kapasitas } \\
\text { tiap saluran } \\
\text { cukup } \\
\text { untuk } \\
\text { membawa } \\
\text { debit } \\
\text { kebutuhan/ } \\
\text { Rencana } \\
\text { Maksimum }\end{array}$ & 64.6 & 50 & 3,23 & 5 \\
\hline $\begin{array}{l}\text { 2. Tinggi } \\
\text { tanggul } \\
\text { cukup } \\
\text { untuk } \\
\text { menghinda } \\
\text { ri limpahan } \\
\text { limbah } \\
\text { setiap saat } \\
\text { selama } \\
\text { pengoprasi } \\
\text { an } \\
\end{array}$ & 29.1 & 20 & 0,58 & 2 \\
\hline $\begin{array}{l}\text { 3. Semua } \\
\text { perbaikan } \\
\text { saluran } \\
\text { telah } \\
\text { selesai }\end{array}$ & 33.7 & 30 & 1,01 & 3 \\
\hline $\begin{array}{l}\text { Total Bobot } \\
\text { Saluran } \\
\text { Pembawa }\end{array}$ & 46.9 & 100 & 4,82 & 10 \\
\hline
\end{tabular}

\section{Bangunan Pada saluran Pembawa}

Komponen penilaian kondisi bangunan pada saluran pembawa terdiri dari bangunan pengatur (Bagi/Bagi sadap/Sadap) apakah lengkap dan berfungsi setiap saat. Pengukuran debit pada bangunan pengambilan dan tiap bangunan tiap bangunan pengatur apakah dapat dilakukan sesuai rencana DI, Bangunan pelengkap pada saluran sekunder berfungsi dan lengkap serta tidak terjadi sumbatan, dan semua perbaikan bangunan pengatur, mistar ukur, skala liter, tanda muka air, papan operasi, dan bangunan pelengkap telah selesai diperbaiki.

Tabel 4. Penilaian kinerja sistem irigasi Bantimurung pada komponen bangunan pada saluran pembawa.

\begin{tabular}{|c|c|c|c|c|}
\hline \multirow[b]{2}{*}{ Uraian } & \multirow[b]{2}{*}{$\begin{array}{c}\text { Kondisi } \\
\text { Eksisting } \\
(\%)\end{array}$} & \multirow[b]{2}{*}{$\begin{array}{c}\text { Nilai } \\
\text { Bagian } \\
(\%)\end{array}$} & \multicolumn{2}{|c|}{ Indeks Kondisi } \\
\hline & & & $\begin{array}{c}\text { Bobot } \\
\text { Final } \\
(\%)\end{array}$ & $\begin{array}{c}\text { Bobot } \\
\text { Maks } \\
(\%) \\
\end{array}$ \\
\hline (1) & (2) & (3) & (4) & $(5)$ \\
\hline $\begin{array}{l}\text { a. Bangunan } \\
\text { Pengatur } \\
\text { (Bagi/Bagi } \\
\text { sadap/sadap) } \\
\text { lengkap dan } \\
\text { berfungsi. } \\
\end{array}$ & 55 & 100 & 1,10 & 2,00 \\
\hline $\begin{array}{l}\text { b. Pengukuran } \\
\text { debit dapat } \\
\text { dilakukan } \\
\text { sesuai rencana } \\
\text { operasi DI } \\
\end{array}$ & 20 & 100 & 0,5 & 2,50 \\
\hline $\begin{array}{l}\text { c. Bangunan } \\
\text { Pelengkap } \\
\text { berfungsi dan } \\
\text { lengkap } \\
\end{array}$ & 83 & 100 & 1,66 & 2,00 \\
\hline $\begin{array}{l}\text { d. Semua } \\
\text { perbaikan } \\
\text { telah selesai } \\
\end{array}$ & 50,8 & 100 & 1,27 & 2,50 \\
\hline $\begin{array}{c}\text { Total Bobot } \\
\text { Bangunan pada } \\
\text { saluran } \\
\text { Pembawa } \\
\end{array}$ & 50,2 & 100 & 4,53 & 9,00 \\
\hline
\end{tabular}

Hasil penilaian menunjukkan komponen terendah dalam berkonstribusi yaitu pengukuran debit dapat dilkaukan setiap saat $0,5 \%$ dari bobot maks 2,5\% sedangkan yang berkonstribusi tinggi yaitu bangunan pelengkap 1,66\% dari bobot maks $2 \%$. Padahal pengukuran debit yang mengalir pada setiap saluran merupakan hal yang urgent karena untuk mengetahui volume air yang mengalir diperlukan rekaman data yang akurat hal ini dapat memudahkan proses pembagian air.

Kondisi Saluran Pembuangan dan Bangunannya

Penilaian pada kondisi saluran pembuangan dan bangunannya seharusnya dilakukan pada semua saluran pembuangan 
dan bangunannya yang telah dibangun dan berfungsi serta tercantum dalam daftar pemeliharaan. Sedangkan kondisi di lapangan tidak didapatkan data terkait saluran pembuangan hal ini di sebabkan karena yang menjadi saluran pembuagan pada irigasi Bantimurung ialah sungaisungai kecil kemudian diteruskan sampai ke laut, sehingga tidak terdapat bangunan pada saluran pembuangan. Sehingga salah satu cara untuk memperoleh data tersebut dilakukan digitasi aliran sungai pada data citra daerah irigasi bantimurung. Penilaian ini dapat diuraikan sebagaimana pada Tabel 5.

Tabel 5. Penilaian kinerja sistem irigasi Bantimurung pada komponen saluran pembuangan dan bangunannya.

\begin{tabular}{|c|c|c|c|c|}
\hline \multirow[b]{2}{*}{ Uraian } & \multirow{2}{*}{$\begin{array}{c}\text { Kondisi } \\
\text { Eksisting } \\
(\%)\end{array}$} & \multirow{2}{*}{$\begin{array}{c}\text { Nilai } \\
\text { Bagian } \\
(\%)\end{array}$} & \multicolumn{2}{|c|}{$\begin{array}{c}\text { Indeks } \\
\text { Kondisi }\end{array}$} \\
\hline & & & $\begin{array}{c}\text { Bobot } \\
\text { Final } \\
(\%) \\
\end{array}$ & $\begin{array}{c}\text { Bobot } \\
\text { Maks } \\
(\%) \\
\end{array}$ \\
\hline (1) & (2) & (3) & (4) & (5) \\
\hline $\begin{array}{l}\text { 1. Semua saluran } \\
\text { pembuangan } \\
\text { dan } \\
\text { bangunannya } \\
\text { telah } \\
\text { dibangun dan } \\
\text { terantum } \\
\text { dalam daftar } \\
\text { pemeliharaan } \\
\text { serta telah } \\
\text { diperbaiki dan } \\
\text { berfungsi. } \\
\end{array}$ & 0 & 75 & 0 & 3,00 \\
\hline $\begin{array}{l}\text { Tidak ada } \\
\text { masalah banjir } \\
\text { yang } \\
\text { menggenangi }\end{array}$ & 66 & 25 & 0,66 & 1,00 \\
\hline $\begin{array}{c}\text { Total Bobot } \\
\text { Saluran } \\
\text { Pembuangan dan } \\
\text { Bangunannya } \\
\end{array}$ & 66 & 100 & 0,66 & 4,00 \\
\hline
\end{tabular}

Saluran pembuangan DI Bantimurung masih berupa saluran tanah karena terbentuk secara alami sehingga tanggul saluran pembuangan masih berupa tanggul tanah. Oleh karena itu tinggi tanggul, elevasi tanggul, kestabilan tanggul tersebut tidak direnacakan.

Pada daerah irigasi Bantimurung lahan sawah yang berada di kecamatan Maros Baru, Simbang dan Bontoa sering mengalami banjir pada musim hujan hal ini disebabkan karena besarnya debit yang mengalir di saluran dan besarnya intensitas hujan sehingga pada musim hujan lahan pertanian (Sawah) tergenangi sekitar $\geq 20$ $\mathrm{cm}$. Akan tetapi air tidak menggenangi sawah dalam jangka waktu yang lama setalah 6 hari air tidak lagi menggenagi areal pertanian. Data ini di peroleh dari hasil wawancara pada setiap kelompok P3A DI Bantimurung.

\section{Jalan Masuk/Inspeksi}

Komponen penilaian kondisi jalan masuk/inspeksi terdiri dari kondisi jalan masuk/inspeksi ke banguan utama, jalan masuk/inspeksi sepanjang saluran pembawa, dan jalan masuk ke saluran maupun bangunan dapat dicapai dengan mudah. Penilaian ini dapat diuraikan sebagaimana pada Tabel 6 .

Tabel 6. Penilaian kinerja sistem irigasi Bantimurung pada komponen saluran jalan masuk/Inspeksi.

\begin{tabular}{ccccc}
\hline Uraian & $\begin{array}{c}\text { Kondisi } \\
\text { Eksisting } \\
(\boldsymbol{\%})\end{array}$ & $\begin{array}{c}\text { Nilai } \\
\text { Bagian } \\
(\mathbf{\%})\end{array}$ & $\begin{array}{c}\text { Indeks Kondisi } \\
\text { Fobot } \\
(\mathbf{\%})\end{array}$ & $\begin{array}{c}\text { Bobot } \\
\text { Maks } \\
(\boldsymbol{\%})\end{array}$ \\
\hline \multicolumn{1}{c}{$(1)$} & $(2)$ & $(3)$ & $(4)$ & $(5)$ \\
\hline $\begin{array}{l}\text { 1. Jalan masuk ke } \\
\text { bangunan } \\
\text { utama dalam } \\
\text { kondisi baik }\end{array}$ & 98 & 50 & 1,96 & 2,00 \\
\hline $\begin{array}{l}\text { 2. Jalan inspeksi } \\
\text { dan jalan } \\
\text { setapak } \\
\text { sepanjang } \\
\text { saluran telah } \\
\text { diperbaiki }\end{array}$ & 73,5 & 25 & 0,74 & 1,00 \\
\hline $\begin{array}{l}\text { 3. Setiap } \\
\text { bangunan dan } \\
\text { saluran yang } \\
\text { dipelihara dapat } \\
\text { dicapai dengan } \\
\text { mudah }\end{array}$ & 60,8 & 25 & 0,61 & 1,00 \\
\hline $\begin{array}{l}\text { Total Bobot Jalan } \\
\text { Masuk/Inspeksi }\end{array}$ & 82,5 & 100 & 3,30 & 4,00 \\
\hline
\end{tabular}

Jalan masuk/inspeksi ke bangunan utama (bendung) merupakan jalan poros Kabupaten Maros-Bone. Pada DI Bantimurung Terdapat 13 saluran, baik itu saluran primer dan sekunder, kemudian terdapat 46 buah bangunan baik itu bagi sadap maupun sadap. Namun untuk mengaksesnya hanya terdapat 28 bangunan yang dapat diakses dengan mudah 
menggunakan kendaraan roda dua, ada 9 buah bangunan dan 2 saluran yang sulit untuk diakses dengan kendaraan dan berjalan kaki disebabkan karena jalan inspeksi hanya berupa tanggul tanah atau pematang sawah yang sering banjir karena limpasan air dari sawah atau air dari saluran.

\section{Perumahan dan Gudang}

Komponen penilaian kondisi jalan masuk/inspeksi terdiri dari apakah kantor, perumahan, dan gudang memadai OP Ranting DI antimurung. Kantor Ranting DI Bantimurung di tempati oleh Pengamat, Mantri/Juru, PPS dan PPA kondisi kantor tersebut dalam keadaan baik dan memadai hanya saja terdapat beberapa keretakan pada dinding dan kaca pada jendela yang lepas serta halaman kantor yang tidak terawat. Kemudian untuk peralatan yang terdapat di kantor (seperti meja, kursi, lemari, rak buku administrasi, atk dll) tidak memadai serta tidak terawat karena tidak pernah di perbaharui jika terjadi kerusakan.

Rumah dinas hanya tersedia untuk PPA dan POB, terdapat 9 rumah dinas dimana 8 rumah untuk PPA dan 1 rumah untuk POB. Dimana setiap rumah dilengkapi dengan ruangan tamu, 2 kamar tidur dan dapur. Akan tetapi 7 rumah PPA dalam kondisi yang rusak dengan persentase $70 \%$ kerusakan dan tidak terawat sedangkan 1 rumah dinas telah rusak berat dan untuk peralatan rumah tidak disediakan oleh dinas tetapi milik pribadi dari pegawai. Penilaian ini dapat diuraikan sebagaimana pada Tabel 7.

Tabel 7. Penilaian kinerja sistem irigasi Bantimurung pada komponen kantor, perumahan dan gudang.

\begin{tabular}{lcccc}
\hline Uraian & $\begin{array}{c}\text { Kondisi } \\
\text { Eksisting } \\
(\%)\end{array}$ & $\begin{array}{c}\text { Nilai } \\
\text { Bagian } \\
(\%)\end{array}$ & $\begin{array}{c}\text { Indeks Kondisi } \\
\text { Bobot } \\
\text { Final } \\
(\%)\end{array}$ & $\begin{array}{c}\text { Bobot } \\
\text { Maks } \\
(\%)\end{array}$ \\
\hline $\begin{array}{l}(1) \\
\text { 1. }\end{array}$ & $(2)$ & $(3)$ & $(4)$ & $(5)$ \\
\hline $\begin{array}{l}\text { Kantor } \\
\text { memadai } \\
\text { untuk: }\end{array}$ & 42,5 & 100 & 0,85 & 2,00 \\
\hline $\begin{array}{l}\text { 2. Perumahan } \\
\text { memadai } \\
\text { untuk: }\end{array}$ & 0 & 100 & 0 & 1,00 \\
\hline 3. Gudang & 66 & 100 & 1,33 & 2,00 \\
\hline
\end{tabular}

memadai

untuk:

Total Bobot

Kantor,

Perumahan,

dan Gudang

\section{Kondisi Produktivitas Tanam}

Komponen penilaian produktivitas tanam yaitu pemenuhan kebutuhan air, luas realisasi tanam, dan produktivitas padi. Sub Komponen pemenuhan kebutuhan air mempunyai nilai $6,20 \%$ dari bobot maks $9 \%$. Hasil penilaian sub komponen realisasi luas tanam mempunyai nilai $1,73 \%$ dari bobot maks 4\%, dan untuk komponen produktivitas padi $1,75 \%$ dari bobot maks $2 \%$. Penilaian ini dapat diuraikan sebagaimana pada Tabel 8 .

Tabel 8. Penilaian kinerja sistem irigasi Bantimurung pada komponen Produktivitas tanam DI bantimurung.

\begin{tabular}{|c|c|c|c|c|}
\hline \multirow[b]{2}{*}{ Uraian } & \multirow[b]{2}{*}{$\begin{array}{c}\text { Kondisi } \\
\text { Eksisting } \\
(\%)\end{array}$} & \multirow[b]{2}{*}{$\begin{array}{c}\text { Nilai } \\
\text { Bagian } \\
(\%)\end{array}$} & \multicolumn{2}{|c|}{ Indeks Kondisi } \\
\hline & & & $\begin{array}{c}\text { Bobot } \\
\text { Final } \\
(\%)\end{array}$ & $\begin{array}{c}\text { Bobot } \\
\text { Maks } \\
(\%)\end{array}$ \\
\hline (1) & (2) & (3) & (4) & (5) \\
\hline $\begin{array}{l}\text { 1. Pemenuhan } \\
\text { Kebutuhan } \\
\text { Air }\end{array}$ & 68,9 & 60 & 6,20 & 9,00 \\
\hline $\begin{array}{ll}\text { 2. } & \text { Realisasi } \\
& \text { Luas Tanam }\end{array}$ & 43,23 & 27 & 1,73 & 4,00 \\
\hline $\begin{array}{l}\text { 3. Produktivitas } \\
\text { Padi }\end{array}$ & 87,57 & 13 & 1,75 & 2,00 \\
\hline $\begin{array}{l}\text { Total Bobot } \\
\text { Produktivitas } \\
\text { Tanaman } \\
\text { (tahun } \\
\text { sebelumnya) }\end{array}$ & 64,53 & 100 & 9,68 & 15 \\
\hline
\end{tabular}

Perhitungan faktor $\mathrm{K}$ dihitung berdasarkan kebutuhan air di pintu tersier dan debit air yang dikeluarkan pada masing-masing Musim Tanam (MT) I, II, dan III. Namun tidak ada data yang akurat mengenai rekaman debit yang mengalir pada saluran sehingga untuk menghitung debit yang tersedia dilakukan dengan menghitung debit dengan manning dan diverifikasi dengan menghitung debit secara langsung di lapangan.

Untuk perhitungan realisasi tanam membutuhkan data areal baku DI Bantimurung, Realisasi Luas Tanam MT 
I,II,III yang di dapatkan dari dinas ketahanan pangan pertanian kabupaten Maros, sedangkan untuk indeks pertanaman (IP) Maksimal 300\%. Serta perhitungan produktivitas padi dihitung berdasarkan luas rencana tanam rata-rata dengan produksi Kondisi yang ada selama MT I,II,III. Data rencana produktivitas di peroleh dari dinas ketahanan pangan kabupaten Maros.

\section{Kondisi Prasarana Penunjang}

Perhitungan kondisi sarana penunjang juga dipengaruhi penilaian terhadap alat transportasi perwakilan balai, pengelola irigasi maupun Petugas Pintu Air (PPA)/ Petugas Operasi Bendung (POB), alat-alat kantor pelaksana OP dan alat komunikasi. Perhitungan penilaian kondisi sarana penunjang dapat dilihat pada Tabel 9.

Tabel 9. Penilaian kinerja sistem irigasi Bantimurung pada komponen Sarana Penunjang DI bantimurung.

\begin{tabular}{|c|c|c|c|c|}
\hline \multirow[b]{2}{*}{ Uraian } & \multirow{2}{*}{$\begin{array}{c}\text { Kondisi } \\
\text { Eksisting } \\
(\%)\end{array}$} & \multirow{2}{*}{$\begin{array}{c}\text { Nilai } \\
\text { Bagian } \\
(\%)\end{array}$} & \multicolumn{2}{|c|}{$\begin{array}{l}\text { Indeks } \\
\text { Kondisi }\end{array}$} \\
\hline & & & $\begin{array}{c}\text { Bobot } \\
\text { Final } \\
(\%) \\
\end{array}$ & $\begin{array}{c}\text { Bobot } \\
\text { Maks } \\
(\%) \\
\end{array}$ \\
\hline (1) & (2) & (3) & (4) & $(5)$ \\
\hline 1. Peralatan O\&P & 29,75 & 100 & 1,19 & 4,00 \\
\hline 2. Transportasi & 0 & 100 & 0 & 2,00 \\
\hline $\begin{array}{l}\text { 3. Alat-alat Kantor } \\
\text { Ranting/Pengamat/ } \\
\text { UPTD } \\
\end{array}$ & 10 & 100 & 0,2 & 2,00 \\
\hline 4. Alat Komunikasi & 0 & 100 & 0 & 2,00 \\
\hline $\begin{array}{c}\text { Total Bobot Sarana } \\
\text { Penunjang }\end{array}$ & 13,9 & & 1,39 & 10 \\
\hline
\end{tabular}

Sub Komponen Peralatan Operasi dan Pemeliharaan mempunyai nilai $1.19 \%$ dari $4,00 \%$ yang diharapkan. Hasil penilaian sub komponen Transportasi mempunyai nilai $0 \%$ dari $2 \%$ yang diharapkan. Hasil penilaian pada sub komponen Transportasi sangat rendah, dikarenakan tidak adanya kendaraan dinas maupun biaya operasional dari Dinas PU bidang PSDA Kabupaten Maros untuk Perwakilan Balai, dan tidak adanya sepeda untuk Petugas Pintu Air/Petugas Operasi Bendung (PPA/POB) dari Dinas PU bidang PSDA Kabupaten Maros.
Penilaian pada sub komponen alatalat kantor mempunyai nilai $0,2 \%$ dari $2 \%$ yang diharapkan, hal ini disebabkan karena perlengkapan kantor dalam kondisi tidak terawat dan tidak memadai untuk pegawai ranting DI Bantimurung. Sedangkan alat komunikasi mendapatkan nilai $0 \%$ dari $2 \%$ yang diharapkan hasil penilaian pada sun komponen alat komunikasi rendah, dikarenakan tidak adanya prasana jaringan komunikasi dari Dinas PU Bidang PSDA Kabupaten Maros. Penilaian sarana penunjang secara keseluruhan menghasilkan nilai $1.39 \%$ dari $10 \%$ yang diharapkan.

\section{Kondisi Organisasi Personalia}

Perhitungan penilaian organisasi personalia dipengaruhi oleh penilaian terhadap organisasi OP, baik dari perwakilan balai, pengelola irigasi, PPA/POB terdapat batasan tanggung jawab dan tugas yang jelas. Kesesuaian jumlah kebutuhan dan status petugas yang sudah menjadi Pegawai Negeri Sipil serta pengetahuan OP oleh perwakilan balai, pengelola irigasi dan PPA/POB juga mempengaruhi penilaian dalam komponen Organisasi personalia ini. Perhitungan penilaian kondisi sarana penunjang dapat dilihat pada Tabel 10.

Tabel 10. Penilaian kinerja sistem irigasi Bantimurung pada komponen Organisasi Personalia DI bantimurung.

\begin{tabular}{|c|c|c|c|c|}
\hline \multirow{2}{*}{ Uraian } & \multirow[b]{2}{*}{$\begin{array}{c}\text { Kondisi } \\
\text { Eksiting } \\
(\%)\end{array}$} & \multirow[b]{2}{*}{$\begin{array}{c}\text { Nilai } \\
\text { Bagian } \\
(\%)\end{array}$} & \multicolumn{2}{|c|}{ Indeks Kondisi } \\
\hline & & & $\begin{array}{c}\text { Bobot } \\
\text { Final } \\
(\%)\end{array}$ & $\begin{array}{c}\text { Bobot } \\
\text { Maks } \\
(\%)\end{array}$ \\
\hline (1) & (2) & (3) & (4) & $(5)$ \\
\hline $\begin{array}{l}\text { 1. Organisasi } \\
\text { O\&P telah } \\
\text { disusun dengan } \\
\text { batasas-batasan } \\
\text { tanggung jawab } \\
\text { dan tugas yang } \\
\text { jelas }\end{array}$ & 61 & 100 & 3,05 & 5,00 \\
\hline 2. Personalia & 61 & 100 & 6,1 & 10 \\
\hline $\begin{array}{l}\text { Total Bobot } \\
\text { Organisasi } \\
\text { Personalia }\end{array}$ & 61 & & 9,15 & 15 \\
\hline
\end{tabular}

Penilaian personalia mengacu pada Peraturan Menteri Pekerjaan Umum No.32/PRT/M/2007 tentang pedoman 
Operasi dan Pemeliharaan (OP) Jaringan Irigasi. Pedoman tersebut menjelaskan tentang jumlah kebutuhan tenaga pelaksana OP yaitu sebagai berikut:

a. Kepala

Ranting/pengamat/UPTD/cabang

dinas/korwil: 1 orang +5 staff per $5.000-7.500 \mathrm{Ha}$.

b. Mantri Juru pengairan: 1 orang per 750 $-1.500 \mathrm{Ha}$.

c. Petugas Operasi Bendung (POB): 1 orang per bendung, dapat ditambah beberapa pekerja untuk bendung besar

d. Petugas Pintu Air (PPA): 1 orang per 35 bangunan sadap dan bangunan bagi pada saluran berjarak antara $2-3 \mathrm{~km}$ atau daerah layanan 150-500 ha.

e. Pekerja/Pekarya Saluran (PS): 1 orang per 2-3 km panjang saluran.

\section{Kondisi Dokumentasi}

Penilaian komponen dokumentasi dipengaruhi oleh tersedianya buku data DI, peta maupun gambar-gambar pada dinding kantor, gambar pelaksana maupun skema jaringan. Perhitungan penilaian kondisi sarana penunjang dapat dilihat pada Tabel 11.

Tabel 11. Penilaian kinerja sistem irigasi Bantimurung pada komponen Dokumentasi DI bantimurung.

\begin{tabular}{|c|c|c|c|c|}
\hline \multirow[b]{2}{*}{ Uraian } & \multirow{2}{*}{$\begin{array}{c}\text { Kondisi } \\
\text { Eksiting } \\
\quad(\%)\end{array}$} & \multirow{2}{*}{$\begin{array}{c}\text { Nilai } \\
\text { Bagian } \\
(\%)\end{array}$} & \multicolumn{2}{|c|}{$\begin{array}{l}\text { Indeks } \\
\text { Kondisi }\end{array}$} \\
\hline & & & $\begin{array}{c}\text { Bobot } \\
\text { Final } \\
(\%) \\
\end{array}$ & $\begin{array}{c}\text { Bobot } \\
\text { Maks } \\
(\%) \\
\end{array}$ \\
\hline$(1)$ & (2) & (3) & (4) & $(5)$ \\
\hline 1. Buku data DI & 51 & 20 & 1,02 & 2,00 \\
\hline $\begin{array}{l}\text { 2. Peta dan } \\
\text { Gambar }\end{array}$ & 34,3 & 20 & 1,03 & 3,00 \\
\hline $\begin{array}{c}\text { Total Bobot } \\
\text { Dokumentasi }\end{array}$ & 54,6 & 100 & 2,73 & 5,00 \\
\hline
\end{tabular}

Buku data DI Bantimurung dibuat pada tahun 1990 untuk kelengkapan buku data DI termasuk dalam kategori baik karena di dalam buku tersebut banyak memuat informasi seperti inventarisasi saluran, pintu air, bangunan ukur, bangunan pelengkap, akan tetapi data-data tersebut tidak pernah di perbaharui terkait masalah kondisi bangunannya. Sedangkan kelengkapan data dinding di kantor hanya terdapat 4 peta yang terpasang yaitu peta skema jaringan, peta skema ploting tenaga kerja, peta struktur organisasi dan peta kalender tanam, namun peta yang tersedia di kantor ranting tidak di perbaharui secara rutin sehingga terdapat beberapa pintu air yang tidak terinformasikan dari peta skema jaringan tersebut. Untuk skema ploting kegiatan pemeliharaan belum terdapat di kantor ranting DI Bantimurung.

\section{Kondisi kelembagaan IP3A/GP3A/P3A}

Penilaian Perkumpulan Petani Pemakai Air meliputi Gabungan P3A (GP3A). Perhitungan penilaian kondisi sarana penunjang dapat dilihat pada Tabel 12.

Tabel 12. Penilaian kinerja sistem irigasi Bantimurung pada komponen IP3A/GP3A/P3A DI Bantimurung.

\begin{tabular}{|c|c|c|c|c|}
\hline \multirow[b]{2}{*}{ Uraian } & \multirow[b]{2}{*}{$\begin{array}{l}\text { Kondisi } \\
\text { Eksiting } \\
\quad(\%)\end{array}$} & \multirow[b]{2}{*}{$\begin{array}{l}\text { Nilai } \\
\text { Bagian } \\
(\%)\end{array}$} & \multicolumn{2}{|c|}{ Indeks Kondisi } \\
\hline & & & $\begin{array}{c}\text { Bobot } \\
\text { Final } \\
(\%)\end{array}$ & $\begin{array}{c}\text { Bobot } \\
\text { Maks } \\
(\%)\end{array}$ \\
\hline$(1)$ & $(2)$ & (3) & (4) & $(5)$ \\
\hline $\begin{array}{l}\text { 1. GP3A/IP3A } \\
\text { sudah Berbadan } \\
\text { Hukum }\end{array}$ & 85.7 & 15 & 1,29 & 1,50 \\
\hline $\begin{array}{ll}\text { 2. } & \text { Kondisi } \\
\text { kelembagaan } \\
\text { GP3A/IP3A }\end{array}$ & 100 & 5 & 0,50 & 0,50 \\
\hline $\begin{array}{l}\text { 3. Rapat Ulu- } \\
\text { ulu/P3A } \\
\text { Desa/GP3A/IP3 } \\
\text { A dengan } \\
\text { Ranting/Penga } \\
\text { mat/UPTD } \\
\end{array}$ & 40 & 20 & 0,8 & 2 \\
\hline $\begin{array}{ll}\text { 4. } & \text { GP3A/IP3A } \\
\text { aktif mengikuti } \\
\text { survey/penelusa } \\
\text { ran jaringan } \\
\end{array}$ & 80 & 10 & 0,8 & 1 \\
\hline $\begin{array}{ll}\text { 5. } & \text { Partisipasi } \\
\text { GP3A/IP3A } \\
\text { dalam } \\
\text { perbaikan } \\
\text { jaringan dan } \\
\text { penanganan } \\
\text { bencana alam. } \\
\end{array}$ & 85 & 20 & 1,7 & 2 \\
\hline $\begin{array}{ll}6 . & \text { Iuran } \\
\text { GP3A/IP3A } \\
\text { digunakan } \\
\text { untuk perbaikan } \\
\text { jaringan } \\
\end{array}$ & 70 & 20 & 1,4 & 2 \\
\hline $\begin{array}{l}\text { 7. Partisipasi } \\
\text { P3A/GP3A/IP3 } \\
\text { A dalam } \\
\text { perencanaan } \\
\text { tata tanam dan }\end{array}$ & 80 & 10 & 0,8 & 1 \\
\hline
\end{tabular}




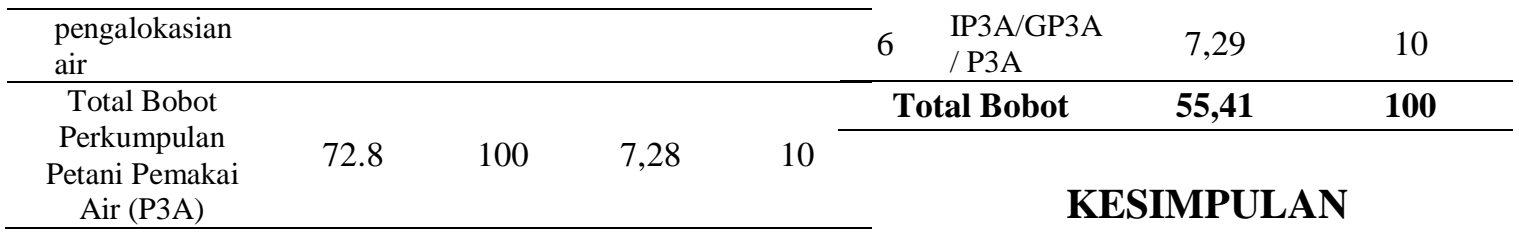

GP3A DI Bantimurung berjumlah 6 Gabungan dan sudah berbadan hukum sejak tahun 2002, namun untuk IP3A DI Bantimurung belum berbadan hukum sejak berdiri tahun 2008 sampai sekarang Sehingga nilai yaitu $85,7 \%$. Konstribusi terendah ialah penilaian untuk rapat uluulu/P3A desa/GP3A/IP3A $0.8 \%$, berdasarkan hasil wawancara GP3A dan P3A tidak mempunyai jadwal pertemuan rutin. Berdasaran wawancara rapat hanya akan dilakukan jika memasuki masa tanam untuk membahas rencana tanam, kebutuhan air dan pengalokasian air.

\section{Penilaian Kinerja Sistem Irigasi Utama DI Bantimurung}

Hasil Perhitungan Penilaian Kinerja Sistem Irigasi Daerah Irigasi (DI) masuk dalam kurang dan perlu perhatian $(54.41 \%)$. Nilai tersebut, berdasarkan Pedoman Peraturan Menteri Pekerjaan Umum nomor 32/PRT/M/2007 Tanggal 11 September 2007. Perhitungan Penilaian Kinerja Sistem Irigasi DI Bantimurung secara terperinci dapat dilihat pada tabel 13. Pada 6 aspek indikator penilaian yang paling banyak berkontribusi dalam penilaian yaitu komponen Organisasi Personalia dan yang paling kurang berkontribusi yaitu komponen Sarana Penunjang.

Tabel 13. Rekapitulasi Penilaian Kinerja Sistem Irigasi Utama DI Bantimurung.

\begin{tabular}{|c|c|c|c|}
\hline No & Uraian & $\begin{array}{c}\text { Bobot Final } \\
(\%)\end{array}$ & $\begin{array}{c}\text { Bobot } \\
\text { Mask }(\%) \\
\end{array}$ \\
\hline (1) & (2) & (3) & (4) \\
\hline 1 & $\begin{array}{l}\text { Prasarana } \\
\text { Fisik }\end{array}$ & 25,17 & 45 \\
\hline 2 & $\begin{array}{l}\text { Produktivit } \\
\text { as Tanam }\end{array}$ & 9,68 & 15 \\
\hline 3 & $\begin{array}{l}\text { Sarana } \\
\text { Penunjang }\end{array}$ & 1,39 & 10 \\
\hline 4 & $\begin{array}{l}\text { Organisasi } \\
\text { Personalia }\end{array}$ & 9,15 & 15 \\
\hline 5 & $\begin{array}{l}\text { Dokumenta } \\
\text { si }\end{array}$ & 2,73 & 5 \\
\hline
\end{tabular}

Penilaian Kinerja Sistem Irigasi Daerah Irigasi (DI) Bantimurung dapat disimpulkan sebagai berikut:

1. Dari hasil analis Kinerja Sistem Irigasi DI Bantimurng menggunakan 6 aspek indikator diperoleh kinerja kurang dan perlu perhatian khusus dengan nilai $55,41 \%$.

2. Pada 6 aspek indikator penilaian yang paling banyak berkontribusi dalam penilaian yaitu komponen prasarana fisik dengan nilai kondisi eksisting $25,17 \%$ dan yang paling kurang berkontribusi yaitu komponen dokumentasi dengan nilai kondisi eksisting $2,73 \%$.

\section{DAFTAR PUSTAKA}

Ars, A. 2015. Evaluasi Kinerja Operasi dan Pemeliharaan Sistem Irigasi Bandar Sidoras di Kecamatan Percut Sei Tuan Kabupaten Deli Serdang. Program Studi Keteknikan Pertanian Fakultas Pertanian Universitas Sumatera Utara: Medan.

Barkey, R.A. 2009. Buku Ajar Sistem Informasi Geografis. Fakultas Kehutanan Universitas Hasanuddin. Makassar.

Direktoral Jendral Pengairan. 2010. Standar Perencanaan Irigasi kriteria Perencanaan Saluran Irigasi (KP03). Departemen Pekerjaan Umum. Jakarta.

Direktoral Jendral Pengairan. 2013. Standar Perencanaan Irigasi (KP01). Departemen Pekerjaan Umum. Jakarta.

Harseno, E. dan Vikey I.R.T. 2007. Aplikasi Sistem Informasi Geografis dalam Pemetaan Batas Administrasi, Tanah, Geologi, Penggunaan Lahan, 
Lereng, Daerah Istimewa Yogyakarta dan Daerah Aliran Sungai di Jawa Tengah Menggunakan Software Arcview GIS. Jurusan teknik Spil Fakultas Teknik UKRIM Yogyakarta; Yogyakarta.

Hasriani, S. 2011. Evaluasi Kinerja Jaringan Irigasi Di Saluran Sekunder pada Berbagai Tingkat Pemberian Air di Pintu Ukur.Vol 15 No. 3. Universitas Lampung. Bandar Lampung.

Isnaeni, B.S. 2016. Penerapan Metode Servqual untuk Perbaikan Mutu Pelayanan Pembagian Irigasi. Fakultas Teknik Universitas Pancasakti: Tegal.

Kementrian Pekerjaan Umum dan Perumahan Rakyat. 2017. Penilaian Kinerja Sistem Irigasi (Permukaan) Kewenangan Pusat. Ditjen Sumber Daya air, Direktorat Bina Operasi dan Pemeliharaan, serta Satuan Kerja Direktorat Bina Operasi dan Pemeliharaan, Kementerian Pekerjaan Umum dan Perumahan Rakyat: Jakarta.

Majuar, E. 2013. Partisipasi Petani Dalam Sistem Pengambilan Keputusan Peningkatan Kenerja Jaringan Irigasi. Jurusan Teknik Sipil Politeknik Negri Lhokseumawe; Aceh

Mawardi dan Moch. M. 2006. Desain Hidraulik Bendung Tetap untuk Irigasi Teknis. Alfabeta: Bandung.

Mubarok, C. 2017. Penilaian Kinerja Irigasi Berdasarkan Pendekatan Permen PUPR No.12/Prt/M/2015 dan Metode Masscote dengan Evaluasi Rapid Appraisal Procedure (Rap) di Daerah Irigasi (Studi Kasus Glapan, Jawa Tengah). Jurusan Teknik Sipil. Fakultas Teknik Universitas Islam Sultan Agung: Semarang.
Mujabuddawat, M.A. 2016. Perangkat Sistem Informasi Geografis (SIG) dalam Penelitian IInformasi Arkeologi. Balai Arkeologi MalukuIndonesia; Maluku.

Nasution, N.S. 2017. Hak atas Irigasi Menurut Wahbah Az-Zuhaili (Studi Kasus Desa Panyabungan Tonga Kec. Panyabungan). Skripsi. Universitas Islam Negri. Medan: Medan.

Novitasari, W.N. 2015. Pemetaan Multi Hazards Berbasis Sistem Informasi Geografis di Kabupaten Demak Jawa Tengah. Jurnal Geodepis Vol. 8 No.2. Universitas Diponegoro: Semarang.

Pramono, S. 2017. Evaluasi dan Penentuan Prioritas Rehabilitasi Jaringan Irigasi (Studi Kasus Pada Daerah Irigasi di Kabupaten Brebes). Jurnal. Universitas Islam Sultan Agung. Semarang Vol. 10 No. 2.

Setyawan, C., S. Susanto dan Sukirno. 2011.Evaluasi Kinerja sistem Irigasi. Jurnal Teknotan Vol. 7, No 2.

Sidra, A.T.W. 2012. Skripsi Sistem Informasi Spasial Kondisi Fisik Jaringan Irigasi Bantimurung Kabupaten Maros. Fakultas Pertanian Universitas Hasanuddin: Makassar. 
Jurnal AgriTechno. Vol. 12 (1): 66-77 https://doi.org/10.20956/at.v12i1.187 